\title{
Evaluation and Improvement of Roundabouts in CBD Area at Al-Hilla City
}

\author{
Abdul Kareem Naji Abbood \\ Civil Engineering Department, Faculty of Engineering, University of Babylon, Babylon, Iraq \\ Email: abdulkareemnaji078@gmail.com \\ Aboothar Abdul Hussein Hamzah Al-Tufail \\ Faculty of Engineering, University of Babylon, Babylon, Iraq \\ Email: abother90@gmail.com
}

\begin{abstract}
In the present-day, congestion considers one of the biggest problems experienced by urban areas. This congestion led to form the conflicting movements at intersections, merging, roundabouts, etc. The objective of this study is to investigate the traffic congestion problem at the two selected roundabouts at CBD area in Hilla city. Roundabouts consider safer than the conventional intersections, but it has less capacity than corresponding intersections. In Iraq, several roundabouts were built in the last decade to improve the traffic performance. However, most of these roundabouts are unable to accommodate the rapid growth in traffic volumes and suffer from a serious issue in congestion. Therefore, this study aims to evaluate these roundabouts. The VISSIM simulation software has been used to perform the evaluation analysis for these selected roundabouts. Then, field data have been collected by using two video cameras that installed by using a fabricated equipment. The process of collecting data has lasted for 8 hours at each roundabout. And then, this field data has been used to calibrate the simulation model (VISSIM). After making the required calibration and validation for the simulation model, the developed model was depended to perform the evaluation and find the suitable solution to solve the traffic congestion at these roundabouts.
\end{abstract}

Keywords: Roundabout, Simulation model, Calibration and Validation.

\section{Introduction}

There are many of studies around the world confirm that those roundabouts are safer and more efficient than traditional intersections and they are widely used not only in urban areas but also on high-speed roads throughout the U.S. and India. However, the performance of these roundabouts in state roads in the U.S. and India is somewhat unknown due to the absence of enough knowledge [1]. After that in the U.S., the data was gathered to develop the HCM 2010 [2]. 90\% of these gathered data have been collected from urban and suburban areas to develop this manual [3].

Generally, roundabouts are widely used in different countries as is stated by [4] and shown in Table1. The basic features of roundabout must be generally described for its importance. Figure1 summarized clearly these features.

According to the research studies, roundabouts have been introduced as a brilliant solution to resolve the problems of traffic circles, and this reason is the one behind the wide usage of roundabouts around the world as is reported by [5]. The author also found that roundabouts have proven to be more efficient than traffic circles and, in some cases, 
Journal of University of Babylon for Engineering Sciences, Vol. (26), No. (7): 2018.

signalized and stops controlled intersections. Differences between roundabouts and traffic circles are summarized in Table 2.

Table 1 The number of modern roundabouts in different countries (adapted by [4]).

\begin{tabular}{|l|l|}
\hline The country & The number of modern roundabout \\
\hline France & From 500 to 25,000 in twenty year \\
\hline Denmark & more than 1400 roundabouts up to 2011 \\
\hline Switzerland & approximately 2,000 roundabouts up to 2004 \\
\hline U.S. & from less than 100 in 1997 to about 1,000 in 2007 \\
\hline
\end{tabular}

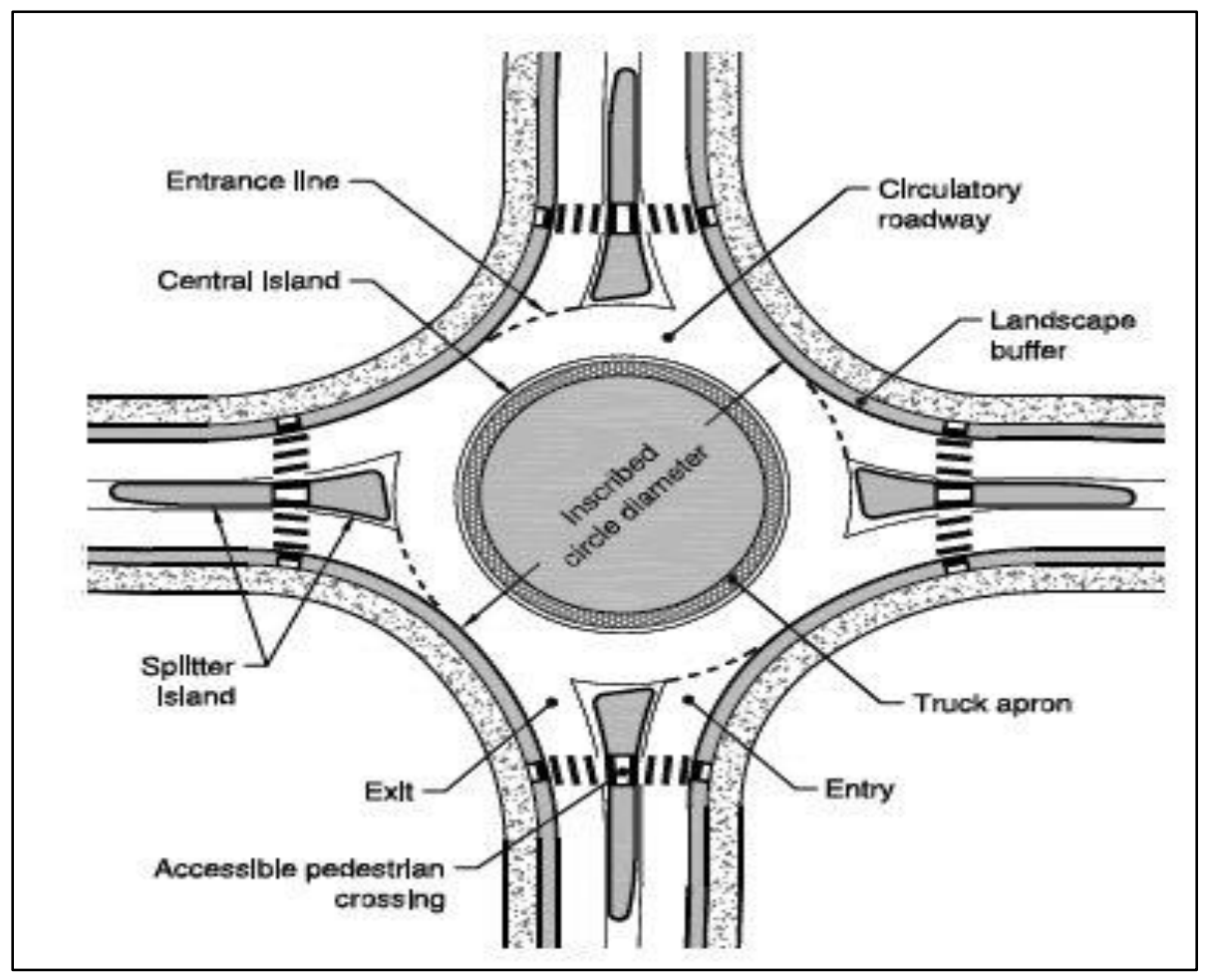

Figure 1 Roundabout features [6].

Table 2: Comparison of roundabouts with traffic circles [6].

\begin{tabular}{|l|l|l|}
\hline Feature & Modern Roundabout & Traffic Circle or Rotary \\
\hline Control at Entry & Yield at entry & $\begin{array}{l}\text { Stop, signal, or give priority to } \\
\text { entering vehicle. }\end{array}$ \\
\hline Operational Characteristics & $\begin{array}{l}\text { Vehicles are sorted by destination at the } \\
\text { approach. Weaving within the circulatory } \\
\text { roadway is minimized. }\end{array}$ & $\begin{array}{l}\text { Weaving is unavoidable and } \\
\text { weaving sections are provided } \\
\text { to accommodate conflicting } \\
\text { movements. }\end{array}$ \\
\hline Deflection & $\begin{array}{l}\text { Large entry angle helps to create entry } \\
\text { deflection to control speed through the } \\
\text { roundabout. }\end{array}$ & $\begin{array}{l}\text { Entry angle likely to be reduced } \\
\text { to allow higher speed at entry. }\end{array}$ \\
\hline Speed & Maintain relatively low speeds (<25 mph) & $\begin{array}{l}\text { Higher speeds allowed (> 25 } \\
\text { mph) }\end{array}$ \\
\hline Circle Diameter & Smaller diameters improve safety. & $\begin{array}{l}\text { Larger diameters allowed. } \\
\text { Small diameter circle } \\
\text { sometimes used for traffic } \\
\text { calming. }\end{array}$ \\
\hline Pedestrian Crossing & No pedestrian activity on central island. & $\begin{array}{l}\text { Some large traffic circles allow } \\
\text { pedestrian crossing to and from } \\
\text { the central island. }\end{array}$ \\
\hline Splitter Island & Required & Optional \\
\hline
\end{tabular}


In a roundabout, the drivers are not required to stop; hence, the facility is more efficient under a broad range of traffic volume as drivers need only to find an acceptable gap in the circulating traffic to merge [4]. Rahmi [7] pointed out that when roundabouts operate at capacity, they offer lower vehicle delays than at other intersection forms. It is unnecessary for traffic at a roundabout to come to a complete stop when there are no conflicts. Figure 2 indicates the comparison between conflict points at intersections and roundabouts.

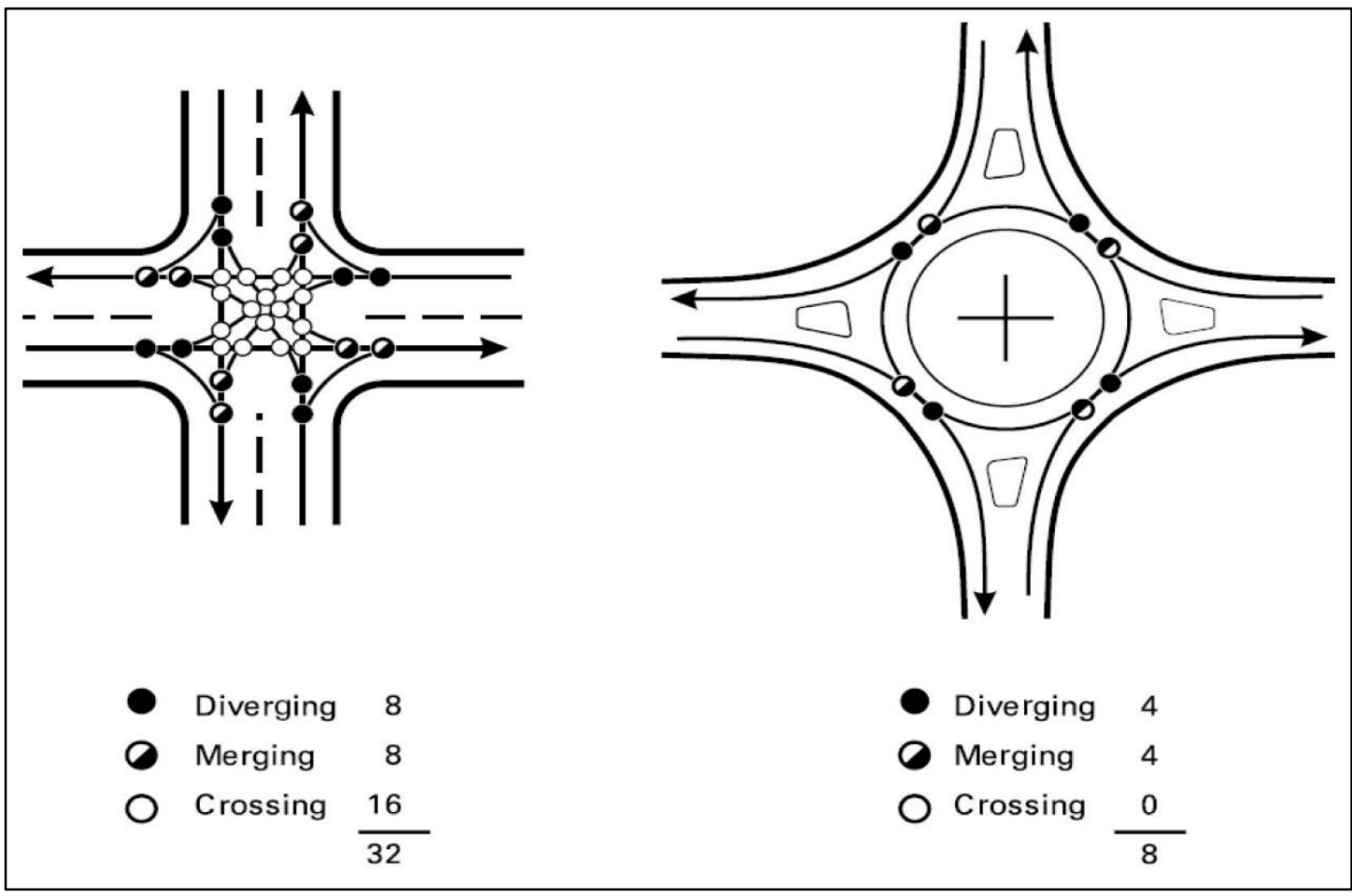

Figure 2 Comparison of vehicle-vehicle conflict points for intersections withFour single-lane approaches [6].

\section{Advantages of Using Roundabouts}

The safety and the mobility are the main reasons that made many countries in Europe and the U.S. to convert their traditional intersections to roundabouts. However, in Europe, the development had come earlier than the U.S \{[8], [9], [10] and [11]\}.

Safety in the roundabout has been produced by eliminating through and left turn movements and thus reduce the number of vehicle conflict points and the angle of impacts [9]. And as the researchers' data stated, the conversion of traditional intersections to roundabouts had the effective role in reducing the resulting severity of injuries and number of fatalities [12].

The conversion of 230 roundabouts reduces the total crashes by $41 \%$ in Australia whereas 83 conversions to roundabouts in France reduce by $78 \%$ of injury crashes and $82 \%$ of fatal crashes. A $45 \%$ reduction for all crashes severities and $81 \%$ for all injury crashes were observed in the U.S. [2]. Regardless of the good safety record, roundabout performance can be ruined if precautions are not considered either during the design or operation phase [13]. This could be seen in countries where roundabout design is a relatively new concept, issues frequently arise that negatively impact the roundabout safety record. 
The second reason behind using of roundabouts is the mobility, this mobility is due to the larger capacity that roundabout able to accommodate than give-way intersections, and signalized junctions because left turns are omitted [14].

\section{Roundabout's Capacity}

Capacity is generally can be defined as "the maximum sustainable hourly flow rate at which persons or vehicles can expected to traverse a point or a uniform section of a lane or roadway during a given time period under prevailing roadway, environmental, traffic and control conditions" [6]. In the roundabout context, capacity is calculated at approach or entry lane level. Conventional roundabout capacity models are usually classified in three mains groups: empirical (regression analysis), stochastic (gap acceptance theory) and microscopic simulation. Each model will be explained in depth.

Firstly, the empirical regression model, also known as conflicting volume model predicts the capacity by means of establishing the regression equation between entry capacity and circulating volume. The prediction is significant under saturated flow condition, besides this methodology could take into account the "pseudo-conflict" caused by exiting vehicles [15]. Many countries use empirical regression model, such as UK, Switzerland, Germany and France. In addition, Federal Highway Administration (FHWA) also proposed this type of models. RODEL and ARCADY are both software packages for the UK model. These models are not applicable for U.S. roundabouts because the UK model is fully empirical and no theoretical basis relating capacity with the geometry characteristics [1].

Secondly, the gap-acceptance model is developed based on the mechanism of accepting and rejecting gaps in the major stream (circulating traffic) by drivers on the minor stream depending on critical headway and follow-up time such as the Australian SIDRA intersection model and the HCM 2010. Though both SIDRA and the HCM 2010 are related to the same approach, their arrival headway distribution for circulating traffic is different. The SIDRA is developed based on a bunched exponential assumption whereas the HCM model is developed based on a simple exponential assumption [16] [2]. Therefore, the SIRDA gives an overestimation of the capacity for U.S. roundabouts because Australian drivers accept considerably smaller gaps than those of the U.S. The HCM 2000 was developed for just single lane roundabout whereas the HCM 2010 in Chapter 21 was developed for both single and two entry lanes approaching one circulatory lane. The main difference between these two types of roundabout depends mainly on two parameters (see the HCM 2010). Therefore, the accuracy of the HCM 2010 model depends on how well these parameters are estimated.

Thirdly, it has been found that the simulation model is the best alternative to empirical and analytical methods. Microscopic models treat each vehicle, pedestrian, etc., as a unique entity with its own goals and behavioral characteristics, each possessing the ability to interact with other entities in the model. These models capture the interactions of real world road traffic through a series of complex algorithms describing car following, lane changing and gap acceptance [2]. Simulation software VISSIM will be adopted in this study to analyze roundabouts. 
Table 3 Principal roundabout software packages [17].

\begin{tabular}{|c|c|c|}
\hline Country & Name & Model \\
\hline U.K. & RODEL & Deterministic \\
\hline U.K. & ARCADY & Deterministic \\
\hline U.K. & PARAMICS & Stochastic \\
\hline Australia & SIDRA & Deterministic \\
\hline Germany & KREISEL & Deterministic \\
\hline Germany & VISSIM & Stochastic \\
\hline U.S.A & INTEGRATION & Stochastic \\
\hline U.S.A & HCS/SYNCHRO & Deterministic \\
\hline France & GIRABASE & Deterministic \\
\hline
\end{tabular}

\section{Data Collection Methodology}

Field data have been collected from Al-Saaha and Al- Muhafadh roundabouts in the Al-Hilla City as shown in Figures $(3,4) .8 \mathrm{~mm}$ video observation cameras have been used for collecting data from these roundabouts. These video cameras enable the researcher to get a continuous and permanent record of all the events, minimize the human errors and need minimum personal support. Thus, the traffic characteristics and their variations can be captured with a high accuracy. The first stage of data collection procedure is the selection of a suitable site that enables cameras from noticing all movements clearly. Al-Saaha and Al-Muhafadh roundabouts are ones of the congested sites in Al-Hilla City.

After getting permission from the security center in the city, vantage points besides these roundabouts have been selected. A (6) meter height steel frame was made for carrying and fixing the cameras with all necessary needs such as a small electrical generator and small LCD screen for observation. The period of 8 hours was collected by the cameras.

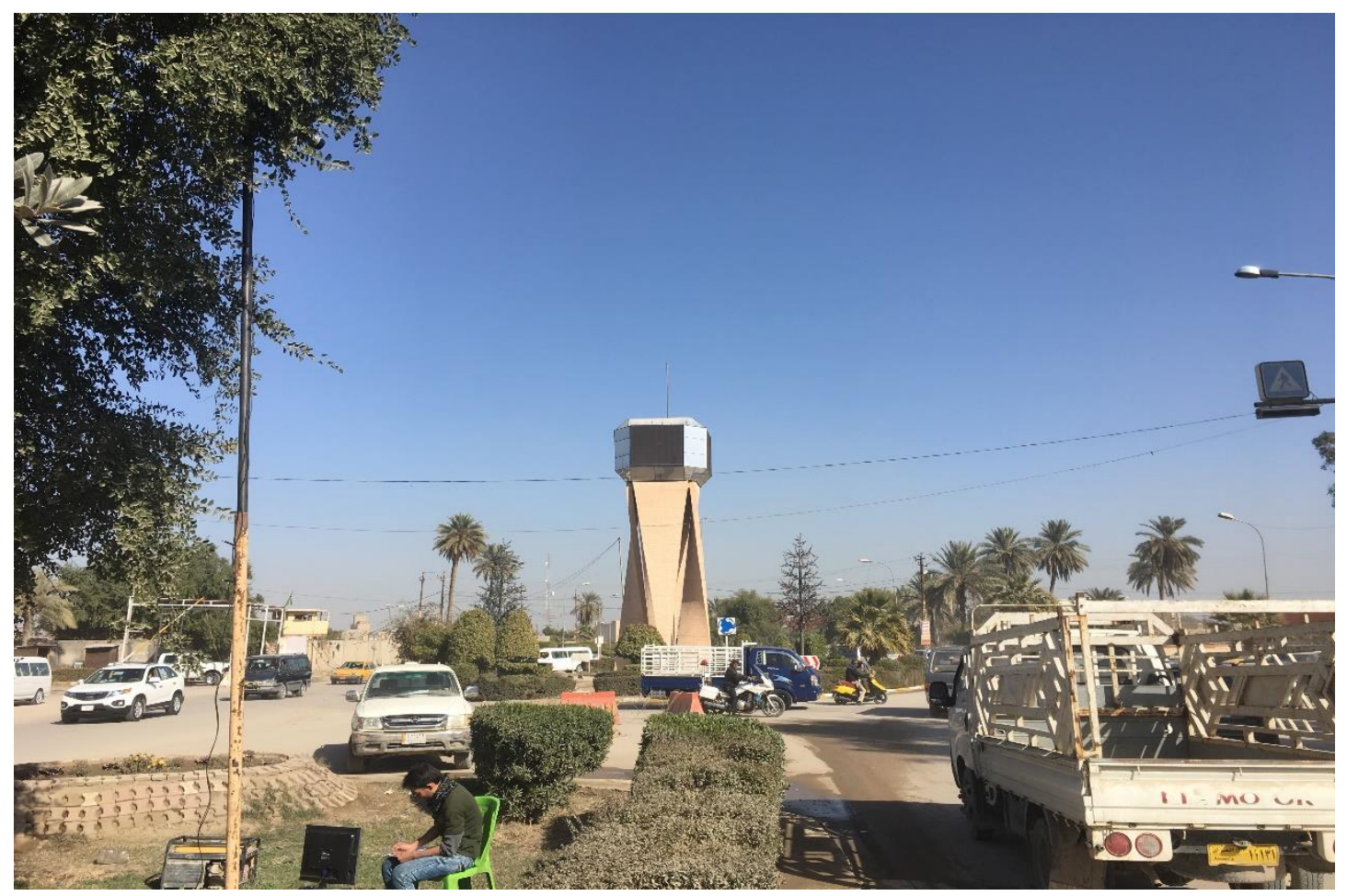

Figure 3: Field Observations of Al-Saaha Square. 


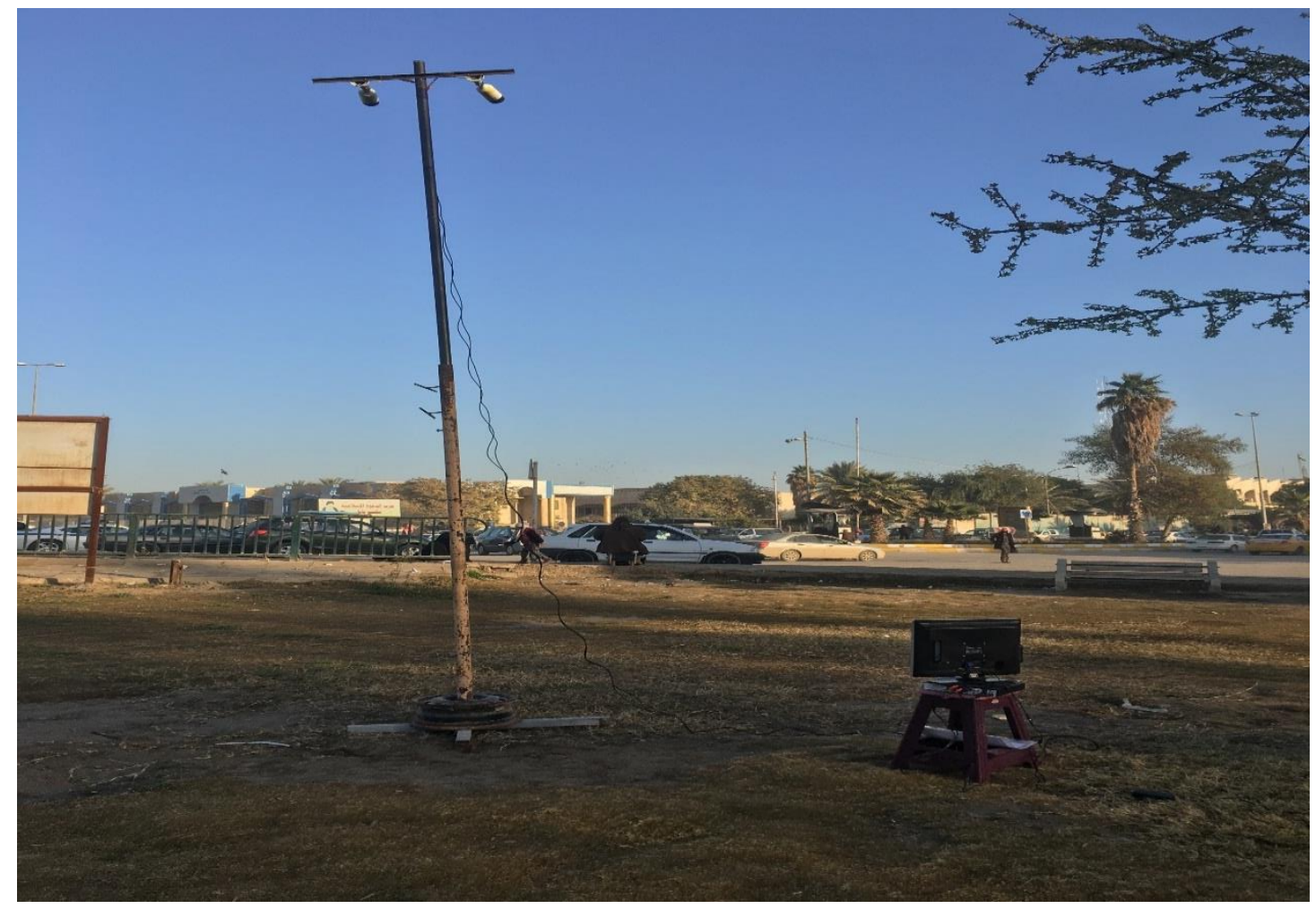

Figure 4 Field Observations of Al- Muhafadh Square.

Field data have been extracted from the video for 8 hours starting from 7:30 A.M to 3:30 P.M. The stage of analysis data consumes time because you have to track each vehicle from the time of entering to the time of exiting. Table $(4,5)$ figure out the results of the analysis. According to these data, it is obvious that the peak hour volume is from 7:30 to $8: 30$ A.M.

The local authority in the city tries to solve the congestion problem by regulating traffic using police traffic officers. However, they failed to mitigate traffic congestion. Therefore, the roundabout has partially closed which creates a huge congestion problem and a noticeable queue length at approaches. 
Journal of University of Babylon for Engineering Sciences, Vol. (26), No. (7): 2018.

Table 4: Field data from Al-Saaha roundabout.

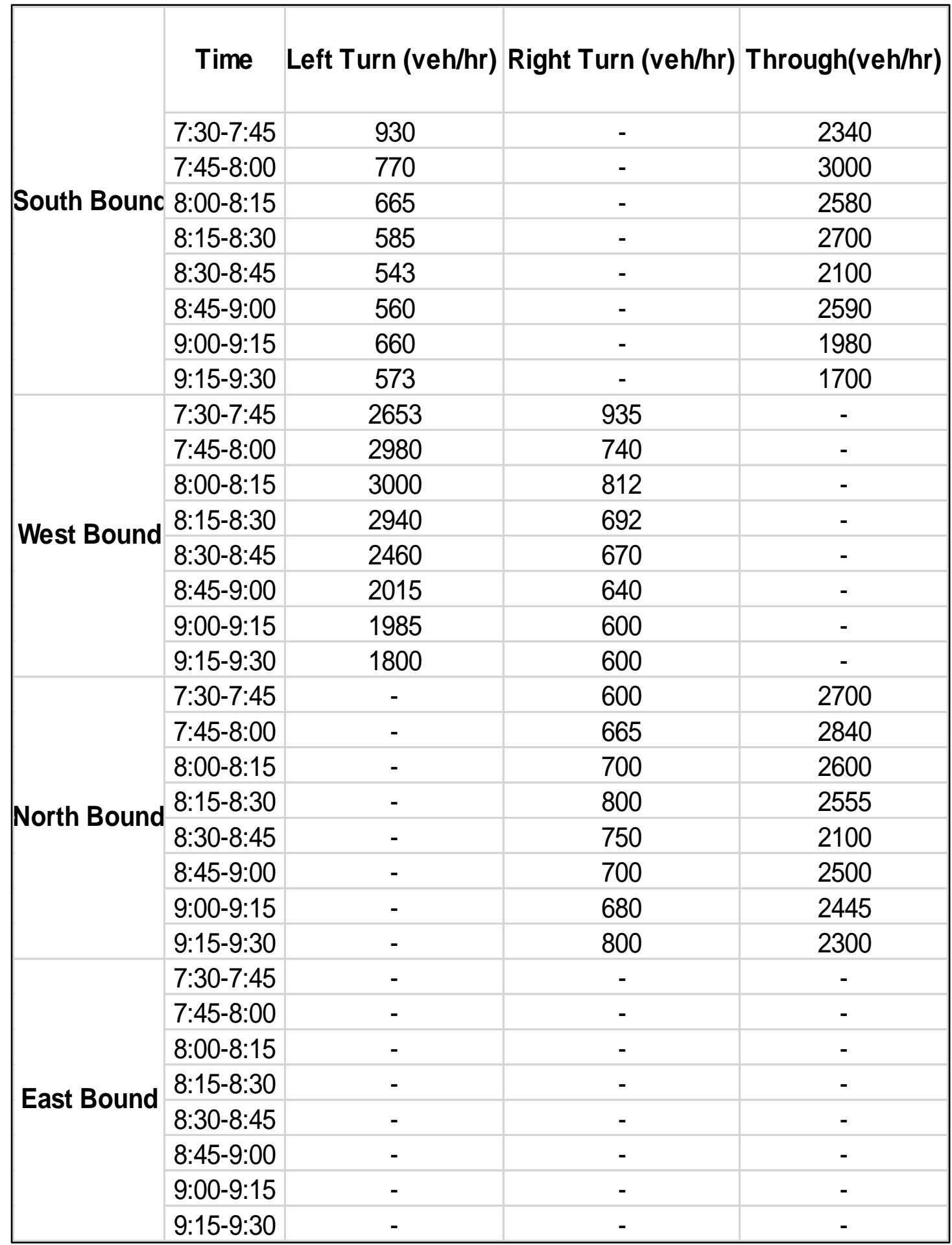


Journal of University of Babylon for Engineering Sciences, Vol. (26), No. (7): 2018.

Table 5: Field data from Al- Muhafadh roundabout.

\begin{tabular}{|c|c|c|c|c|}
\hline \multirow{9}{*}{ South Bound } & Time & Left Turn (veh/hr) & Right Turn (veh/hr) & Through (veh/hr) \\
\hline & $7: 30-7: 45$ & 550 & 397 & 2280 \\
\hline & 7:45-8:00 & 600 & 420 & 2560 \\
\hline & 8:00-8:15 & 580 & 360 & 2580 \\
\hline & 8:15-8:30 & 540 & 344 & 2600 \\
\hline & $8: 30-8: 45$ & 543 & 294 & 2200 \\
\hline & 8:45-9:00 & 560 & 310 & 2480 \\
\hline & $9: 00-9: 15$ & 645 & 285 & 2100 \\
\hline & 9:15-9:30 & 700 & 290 & 1950 \\
\hline \multirow{8}{*}{ West Bound } & $7: 30-7: 45$ & 100 & 1000 & 99 \\
\hline & 7:45-8:00 & 150 & 1250 & 66 \\
\hline & 8:00-8:15 & 144 & 1400 & 70 \\
\hline & $8: 15-8: 30$ & 160 & 1200 & 77 \\
\hline & $8: 30-8: 45$ & 166 & 1350 & 60 \\
\hline & $8: 45-9: 00$ & 123 & 1200 & 50 \\
\hline & 9:00-9:15 & 150 & 1115 & 44 \\
\hline & 9:15-9:30 & 100 & 1100 & 33 \\
\hline \multirow{8}{*}{ North Bound } & $7: 30-7: 45$ & - & 960 & 2612 \\
\hline & 7:45-8:00 & - & 1000 & 2830 \\
\hline & 8:00-8:15 & - & 1213 & 2650 \\
\hline & 8:15-8:30 & - & 980 & 2740 \\
\hline & $8: 30-8: 45$ & - & 1000 & 2400 \\
\hline & 8:45-9:00 & - & 850 & 2500 \\
\hline & 9:00-9:15 & - & 844 & 2445 \\
\hline & 9:15-9:30 & - & 840 & 2300 \\
\hline \multirow{8}{*}{ East Bound } & 7:30-7:45 & - & 655 & 500 \\
\hline & $7: 45-8: 00$ & - & 670 & 580 \\
\hline & 8:00-8:15 & - & 720 & 600 \\
\hline & 8:15-8:30 & - & 650 & 640 \\
\hline & $8: 30-8: 45$ & - & 693 & 480 \\
\hline & 8:45-9:00 & - & 645 & 450 \\
\hline & 9:00-9:15 & - & 630 & 440 \\
\hline & $9: 15-9: 30$ & - & 600 & 420 \\
\hline
\end{tabular}

\section{Developing and calibrating the simulation model}

As discussed previously, simulation models have been proved to be the best tools for evaluating roundabout intersection because of the complexity of driver's behavior at these locations. Moreover, simulation models mimic the reality and different alternatives without any cost and disturbing the traffic. Therefore, PTV VISSIM model has been adopted in this study. Firstly, building a roundabout in the PTV VISSIM could be implemented by nodes and links. Then, adding zones for each direction is to provide origin and destination for each movement. After building the roundabout physically as shown in Figures $(5,6)$, the demand matrix has been supplied with field data. 
Journal of University of Babylon for Engineering Sciences, Vol. (26), No. (7): 2018.

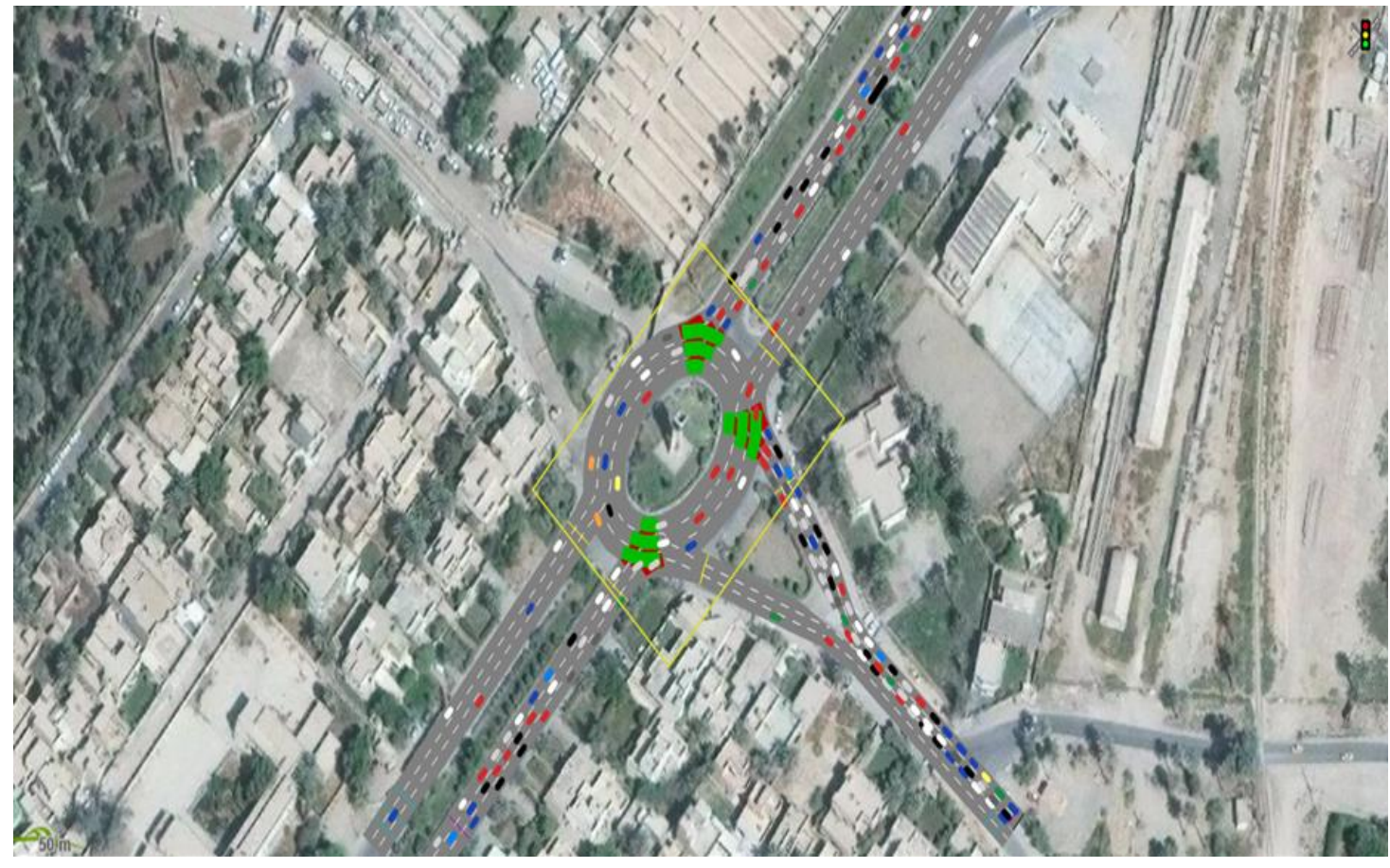

Figure 5 Output screen of PTV VISSIM simulation model of Al-Saaha roundabout.

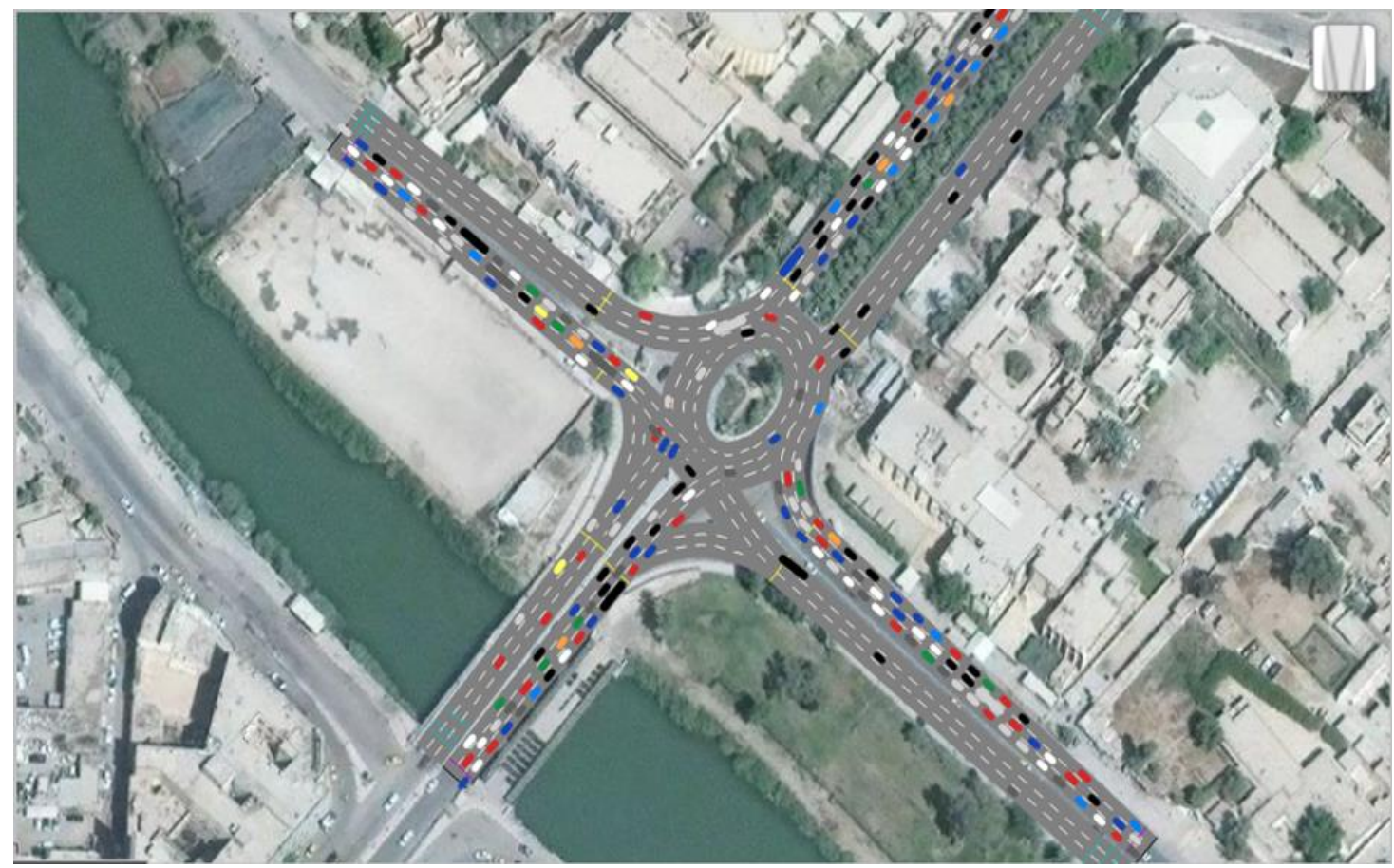

Figure 6 Output screen of PTV VISSIM simulation model of Al- Muhafadh roundabout. 
Journal of University of Babylon for Engineering Sciences, Vol. (26), No. (7): 2018.

Then, the simulated model has been calibrated with the observed data extracted from videos. The results show a good consistency between simulated and filed data as indicated in Figures $(6,7)$.

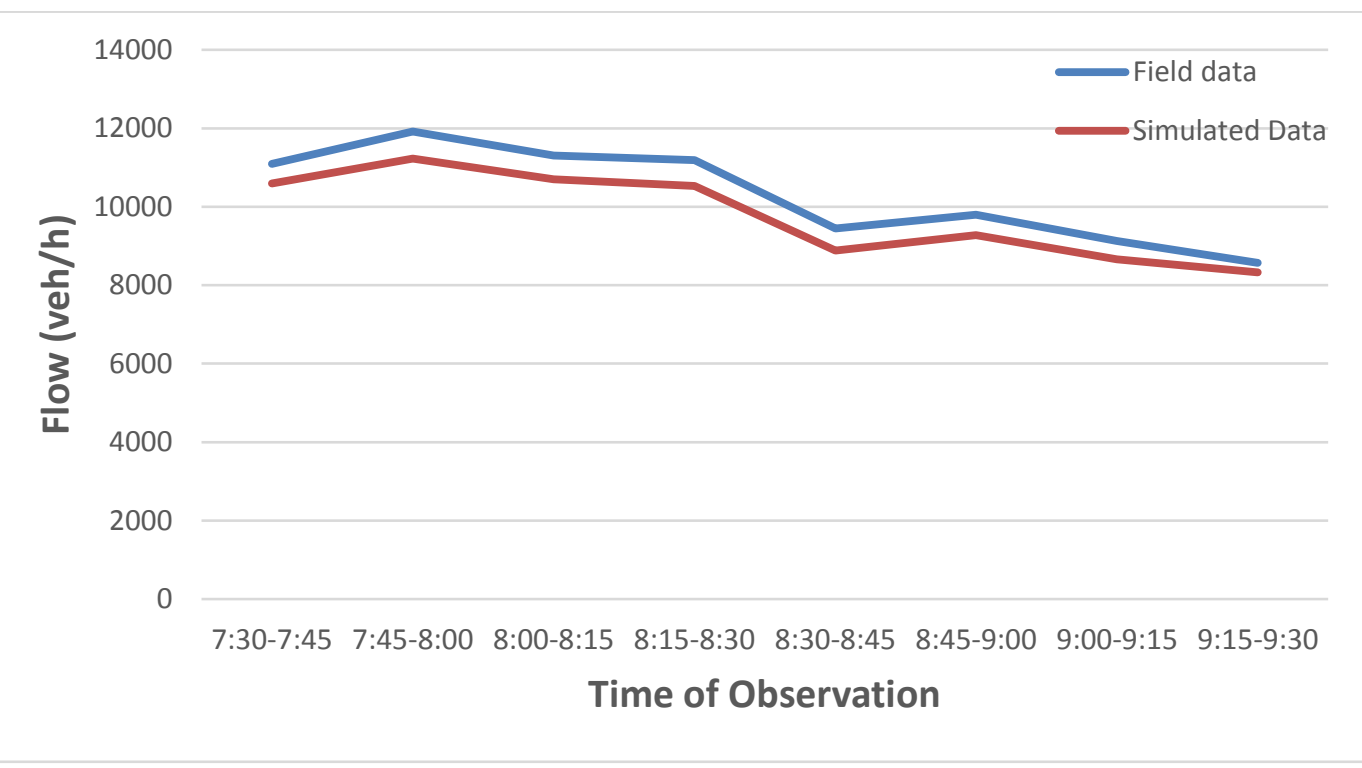

Figure 6: Comparison between field and simulated data of Al-Saaha roundabout.

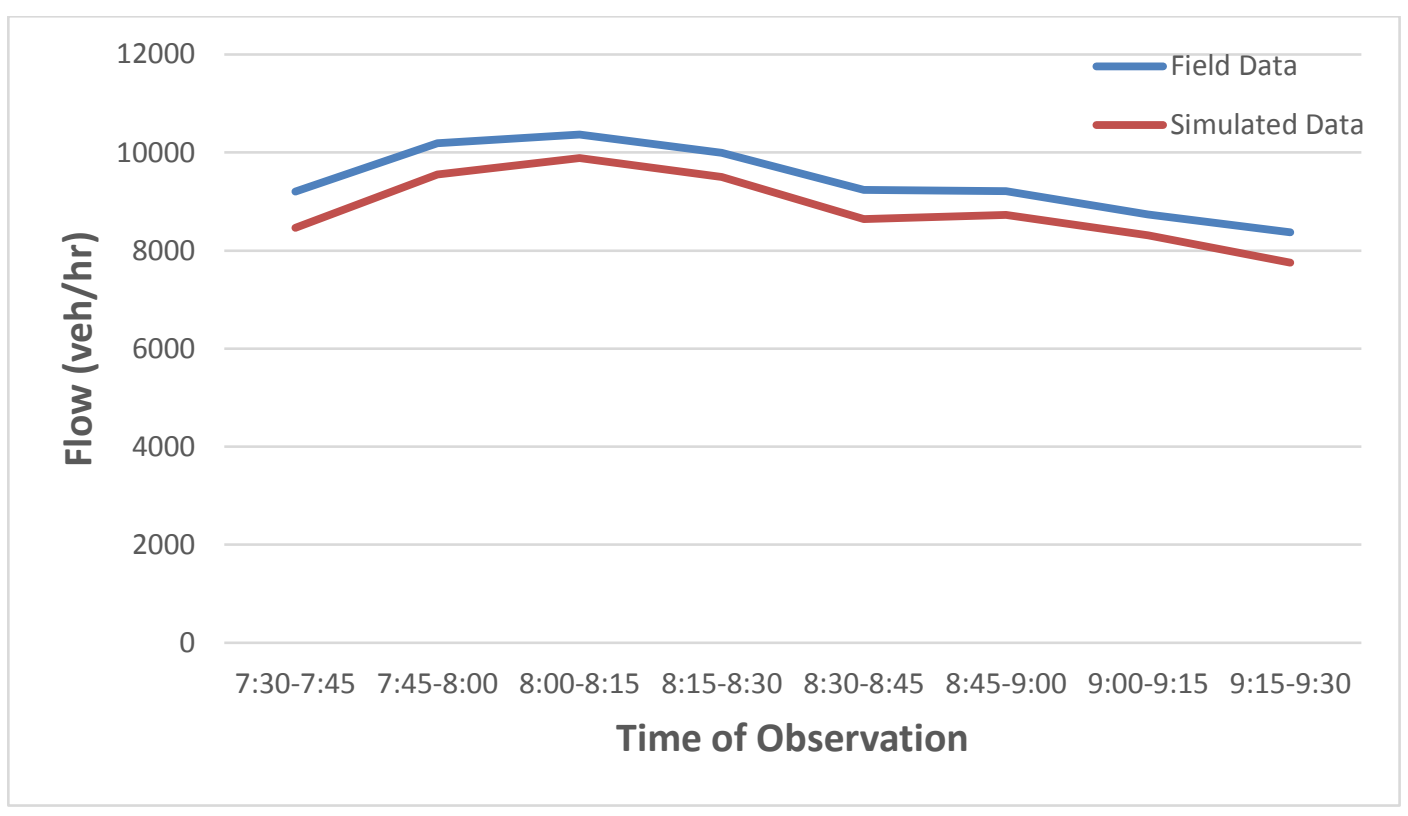

Figure 7: Comparison between field and simulated data of Al- Muhafadh roundabout. 
Journal of University of Babylon for Engineering Sciences, Vol. (26), No. (7): 2018.

\section{Improvement Proposals}

After calibration of the developed models, the suggested scenarios have been applied to improve the capacity of the selected roundabouts.

For Al-Saaha roundabout, it has been found that the best suggestion solution is achieved by making an overpass for the north-south approaches, due to the high traffic volumes at them, and after making these improvements, the level of service will rise from $\mathrm{F}$ to $\mathrm{A}$. The improvement proposal is shown in Figure 8.

For Al-Muhafadh roundabout, it has been found that the best suggestion solution is achieved by applying these steps:

- Making an overpass for the traffic movement upcoming from Merjan hospital towards Al-Sooq.

- Isolating the right turn movement for the west and east approaches by right-turn bypass lanes.

These improvements will make an easy traffic flow and lift the level of service from $\mathrm{F}$ to A. The improvement proposal is shown in Figure 9.

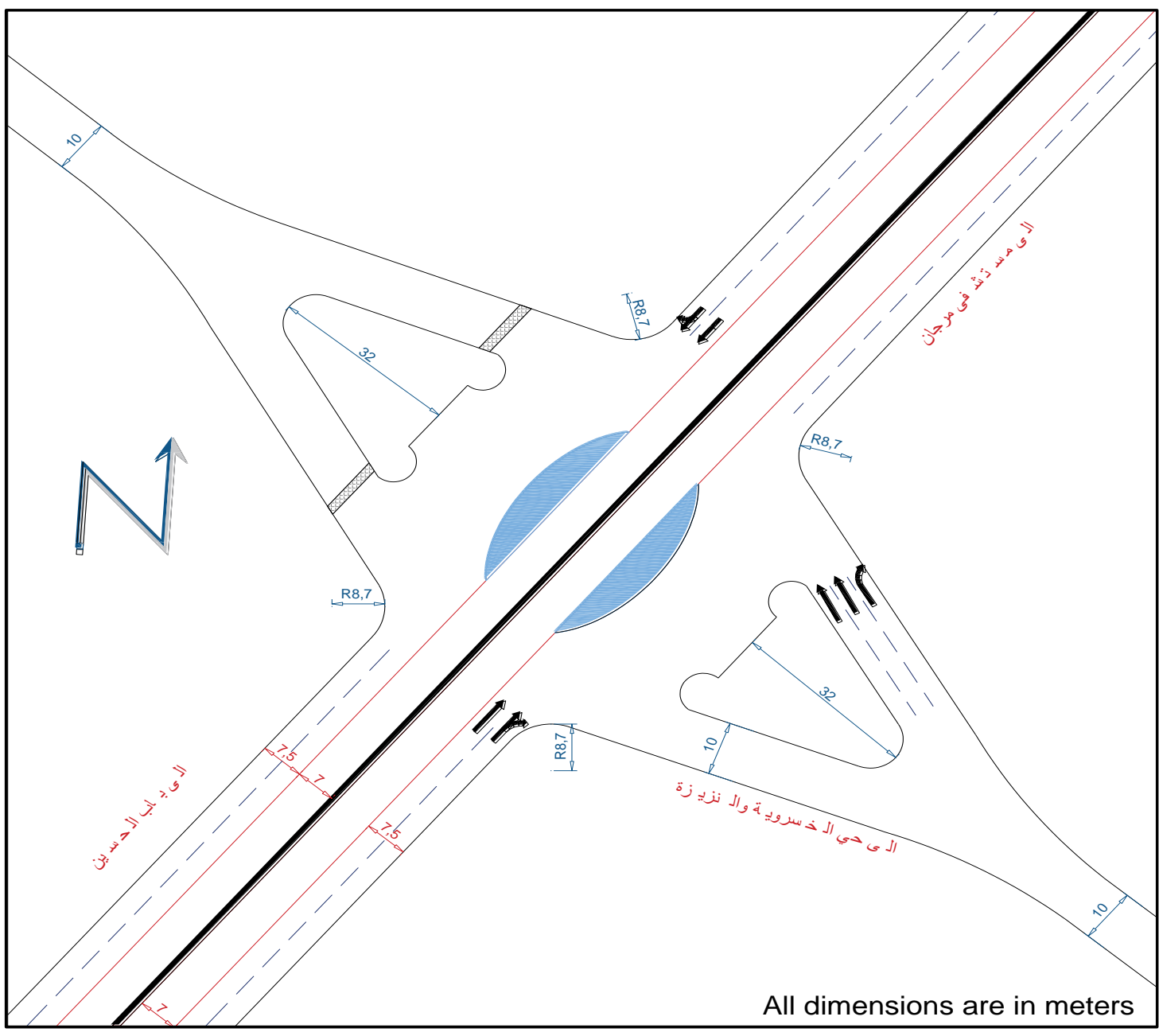

Figure 8: Improvement Proposal for Al-Saaha Roundabout. 


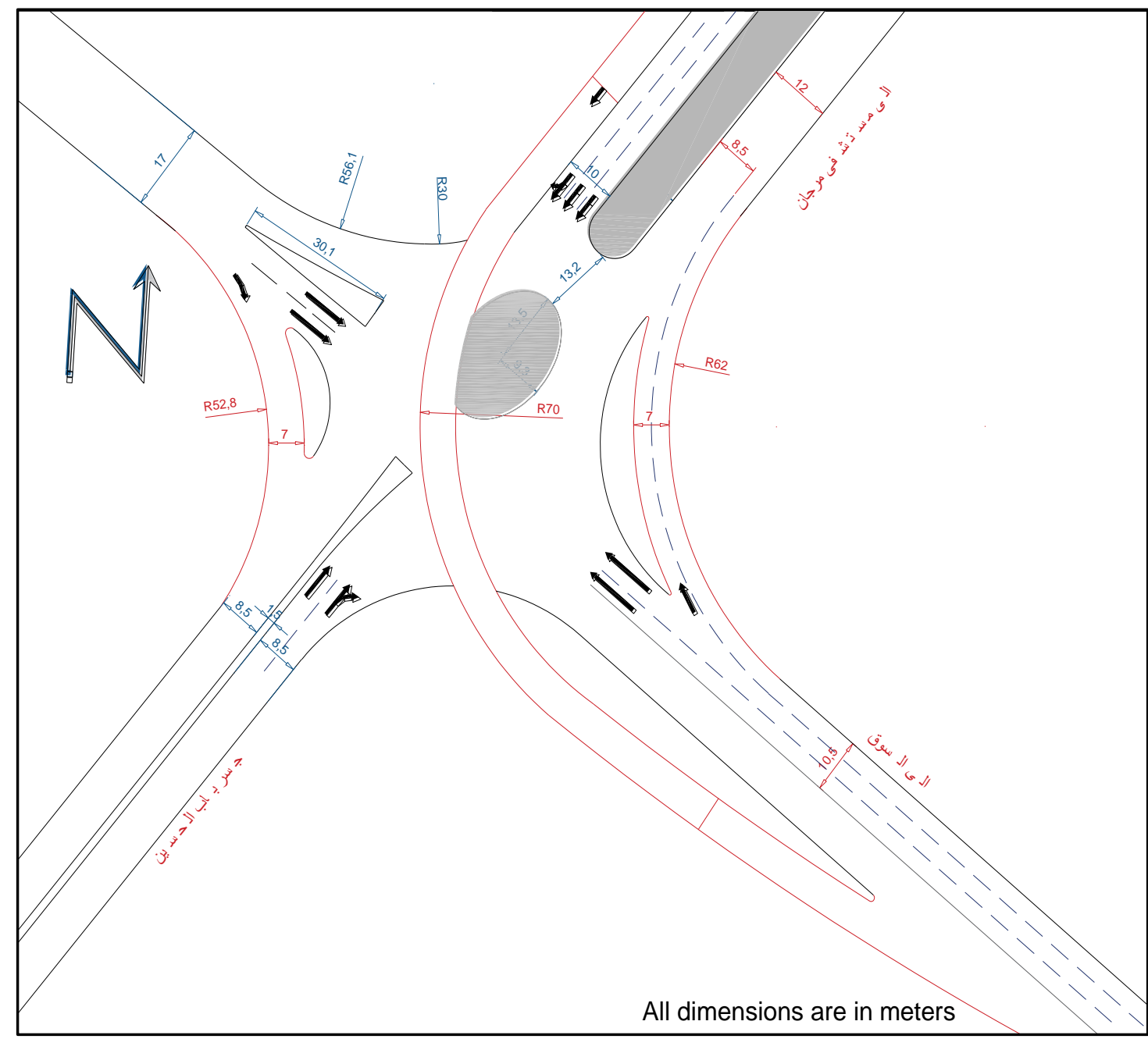

Figure 9: Improvement Proposal for Al-Muhafadh roundabout.

\section{Conclusion}

To sum up, the main points that have been concluded from this study are:

1. According to field data, the capacities of the selected roundabouts are so limited due to the high traffic movements at these locations especially at peak hour periods.

2. Simulation model represents the best solution to model the behavior of roundabout characteristics. This simulated model helps in testing different scenarios close to the reality without any cost of construction in the field.

3. The optimum solution for Al-Saaha roundabout is achieved by making an overpass for the north-south approaches. And for Al-Muhafadh roundabout, it has been found that the best solution is achieved by making an overpass for the traffic movement upcoming from Merjan hospital towards Al-Sooq and isolating the right turn movement for the west and east approaches by right-turn bypass lanes. 
Journal of University of Babylon for Engineering Sciences, Vol. (26), No. (7): 2018.

\section{References}

[1] Ahmad S., Capacity-related Driver Behavior on Modern Roundabouts Built on High-speed Roads. MSc Thesis, Purdue University, West Lafayette, Indiana, 2014.

[2] Rodegerdts L., Blogg M., Wemple E., Myers E., Kyte M., Dixon M., List G., Flannery A., Troutbeck R., Brilon W., Persaud B., Lyon C., Harkey D., and Carter D., Appendixes to NCHRP Report 572: Roundabouts in the United States. NCHRP Web-Only Document 94, Washington, DC, US, 2007.

[3] Day C., Hainen A., and Bullock D., Best Practices for Roundabouts on State Highways. Joint Transportation Research Program, Indiana Department of Transportation and Purdue University. West Lafayette, Indiana, 2013.

[4] Montella A., Turner S., Chiaradonna S., and Aldridge D., Proposals for Improvement of the Italian Roundabout Geometric Design Standard.SIIV-5th International Congress- Sustainability of Road Infrastructures. Procedia-Social and Behavioral Sciences 53, pp.189-202, 2012.

[5] SONE C., the Effects of Behavioural, Geometric and Heavy Vehicle Traffic Flow Characteristics on Capacity and Emissions at Roundabouts. Master thesis, The University of Texas, 2010.

[6] Rodegerdts L. A., Roundabouts: An informational guide (Vol. 672). Transportation Research Board, 2010.

[7] Rahmi A., "Evaluating roundabout capacity, level of service and performance." ITE, Annual Meeting (San Antonio, Texas), 2009.

[8] Daniels S., Brijs T., Nuyts E., and Wets G., Externality of risk and crash severity at roundabouts. Accident Analysis and Prevention, Vol. (42), pp. 1966 - 1973, 2010.

[9] Hels T., and Orozova-Bekkevold I., the Effect of Roundabout Design Features on Cyclist Accident Rate. Accident Analysis and Prevention, Vol. (39), pp. 300-307, 2007.

[10] Perseaud B., Retting R., Garder P., and Lord D., Safety effect of roundabout conversions in the United States: empirical bayes observational before- after study. Transport. Res. Rec., pp. 1-9, 2001.

[11] Flannery A., Geometric Design and Safety Aspects of Roundabouts. Transportation Research Record, pp.76-82, 2001..

[12] Montella A., Identifying Crash Contributory Factors at Urban Roundabouts and Using Association Rules to Explore Their Relationships to Different Crash Types. Accident Analysis and Prevention Vol. (43), pp.1451-1463, 2011.

[13] Montella A., Roundabout in-service Safety Reviews: Safety Assessment Procedure. Transportation Research Record, pp. 40-50, 2007.

[14] Elvik R. and Vaa T., the Handbook of Road Safety Measures. Elsevier, 1078, 2004.

[15] Al-Madani HMN, Capacity of large dual and triple-lanes roundabouts during heavy demand conditions. Arabian Journal for Science and Engineering. 38(3):491$505,2012$. 
Journal of University of Babylon for Engineering Sciences, Vol. (26), No. (7): 2018.

[16] Akcelik R., A Review of Gap-Acceptance Capacity Models. 29 $9^{\text {th }}$ Conference of Australian Institutes of Transport Research. University of South Australia, Adelaide, Australia, 2011.

[17] Gallelli V. and Vaiana R., Roundabout Intersections: Evaluation of Geometric and Behavioural Features with VISSIM. Proceedings of TRB National Roundabout Conference. Kansas City, Missouri, USA, 2008. 
Journal of University of Babylon for Engineering Sciences, Vol. (26), No. (7): 2018.

\section{تقييم وتحسين التقاطعات الدائرية في منطقة الاعمال المركزية لمدينة الحلة عبد الكريم ناجي عبود أبوذر عبد الحسين حزة الطقيلي جامعة بابل كلية الهنسسة القسم المدني}

abother90@gmail.com abdulkareemnaji078@gmail.com

الخلاصة

في وقتتا الحاضر، بعتبر الازدحام أحد أكبر المشاكل التي تعاني منها المناطق الحضرية. مما يؤدي إلى الى التي

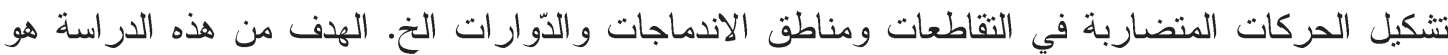

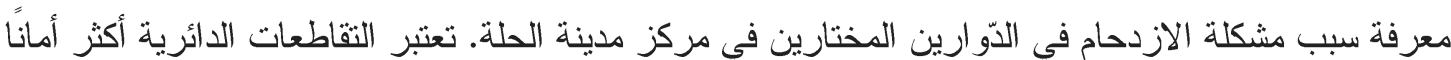

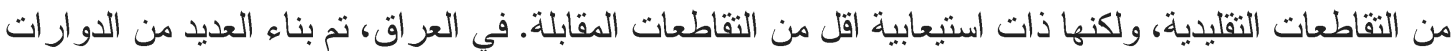

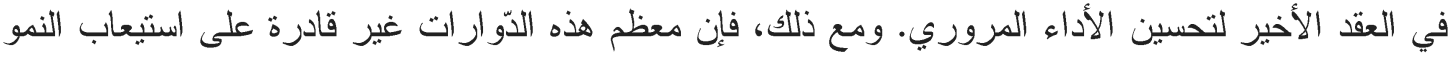

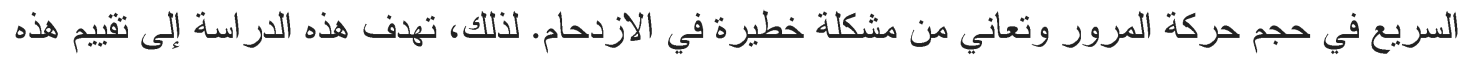

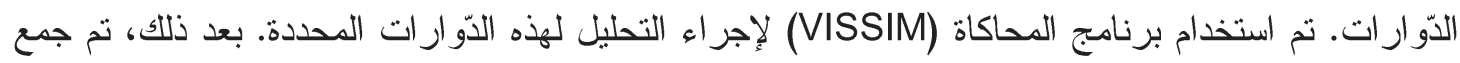

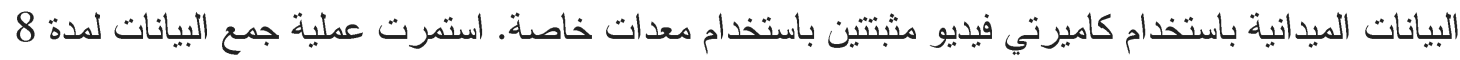

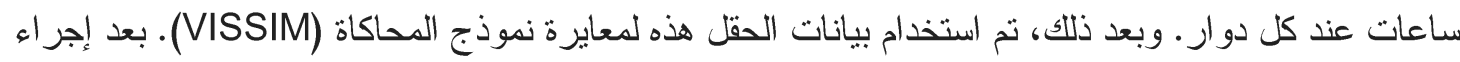

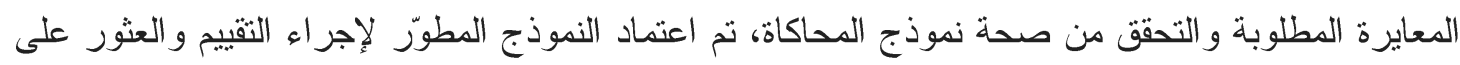
الحل المناسب لحل ازدحام المرور في هذه الدّو ارات. الكلمات الدفتاحية: - الدّو ارات، نموذج المحاكاة، المعايرة و المقبولية. 